\title{
The Effect of Rating Agencies on Herd Behaviour
}

Giovanni Ferri and Andrea Morone

\section{EERI}

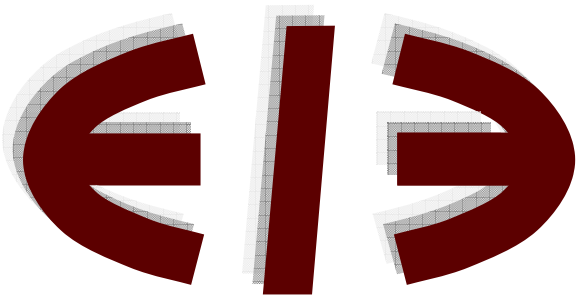

Economics and Econometrics Research Institute Avenue de Beaulieu 1160 Brussels

Belgium

Tel: +322 2993523

Fax: +322 2993523

www.eeri.eu 


\title{
The Effect of Rating Agencies on Herd Behaviour $^{\dagger}$
}

\author{
Giovanni Ferri \\ University of Bari \\ gioferri@gmail.com
}

\author{
Andrea Morone \\ University of Bari \\ a.morone@gmail.com
}

NOVEMBER 2008

\begin{abstract}
This paper purports to provide some evidence on the effect of rating agencies on herding in financial markets. By means of a laboratory experiment, we investigate the effect and interaction between private and public information. Previous experiments showed that lemmings behaviour can survive in a market context where information is private (Hey and Morone, 2004), and that an experimental market can be very volatile and not efficient in transmitting information (Alfarano et al., 2006). We study experimentally, if socially undesirable behaviour - that survives in a market contest may be eliminated owing to the presence of rating agencies.
\end{abstract}

JEL classification: C91, D82, D83.

Keywords: herd behaviour, informational cascades, rating agency, bubble.

\footnotetext{
${ }^{\dagger}$ We would like to thank the University of Bari for funding the experiments reported in this paper. The experiments were run at the laboratory of ESSE at the University of Bari. We are grateful to Paola Buizza for valuable assistance in running the experiments.
} 


\section{Introduction}

The aim of this paper is to study whether the presence of a rating agency can endorse the aggregation process of private information. The theoretical background of our work is given by two models dealing respectively with herd behaviour (Banerjee, 1992) and informational cascades (Bikhchandani, Hirshleifer and Welch, 1992). These models were initially developed in a nonmarket context and showed that imitative behaviour can cause information externalities (Becker, 1991). That may result from private information not being publicly shared. Those models often make strong assumptions about the available information, the choices to make, the timing of decisions, and the symmetry of equilibrium. Specifically, both papers showed that individuals, acting sequentially on the basis of private information and public knowledge on the others' behaviour, may end up choosing the socially undesirable option ${ }^{1}$.

There is a well know and established branch of literature addressing the information aggregation in market contexts. A very early reference is the classic paper by Grossman and Stiglitz (1976, 1980), which showed that uninformed traders can become informed through the price in such a way that private information is aggregated correctly and efficiently ${ }^{2}$.

Experimental economics literature suggests that the market may act as a sort of disciplining device on 'irrational' behaviour in individual contexts (Smith, 1962; Plott and Sunder ,1982). Hey and Morone (2004) emended a simple model of informational cascades in a market contest. This allowed relaxing some of the assumptions about the available information (i.e. subjects can buy information at any time and in any quantity); the choices to make (i.e. subjects can buy or sell assets or they can decide to do nothing); the timing of decisions (i.e. subjects act simultaneously). They showed that whenever complexity (measured by the quality and the quantity of information present in the market) increases, noise (measured by the volatility of prices) increases as well. Consequently herding is less likely when the quality and quantity of information in the market are higher.

\footnotetext{
${ }^{1}$ For some experimental evidence and theoretical developments see Anderson and Holt (1997), Allsopp and Hey (2000), Fiore and Morone (2008), and Morone and Samanidou (2008).

${ }^{2}$ A summary of the progress made by this strand of literature can be found in Plott (2002).
} 
Alfarano et al. (2007) studied an experimental asset market where subjects decided whether to keep their money in a bank account with a constant risk-free interest rate or invest in a risky asset, paying a random dividend. They analyzed whether different degrees of heterogeneity in the information available to the traders are responsible of their observed heterogeneous behaviour, and, ultimately, whether such heterogeneity of strategy plays a crucial role in the empirically identified market inefficiencies. They showed that the experimental assets markets were not efficient in transmitting information, as transaction prices are far away from the fundamental value of the asset. However, the presence of more information in the market has some effects on trading volume and variance.

An interesting issue, that was never investigated experimentally, is the role of rating agencies in their interaction with financial markets. In essence, there seem to be only few theoretical contributions while several papers have addressed empirically the market impact of the rating agencies. Among the former contributions, Millon and Thakor (1985) demonstrate that information gathering agencies may arise in a world of informational asymmetries and moral hazard. According to them, in a setting in which true firm values are certified by screening agents whose payoffs depend on noisy ex post monitors of information quality, the formation of information gathering agencies is justified because it: (1) enables screening agents to diversify their risky payoffs, and (2) allows information sharing. However, Millon and Thakor (1985) assume perfect knowledge by the information gathering agency about the underlying risk of the borrower and do not model the possibility that investors may wish to verify ex post the quality of the information provided by the rating agencies. In a more general setup, one would like to model the effort of and the payoffs to the rating agency. ${ }^{3}$ Still on theoretical grounds, referring to a multiple equilibria set up, Boot et al. (2004) show that the rating is a coordinating mechanism, providing a "focal point" for firms and investors, thanks to the implicit contract relationship (monitorrenegotiate). However, Carlson and Hale (2006) reach opposite conclusions. They build a game

\footnotetext{
${ }^{3}$ For instance, Kuhner (1999) argues that, in a systemic crisis, their payoffs may lead rating agencies to an equilibrium in which they pool "good" borrowers together with "bad" borrowers.
} 
theoretic model of rating agencies in which heterogeneous investors act strategically, predicting that introducing a rating agency to a market that otherwise would have the unique equilibrium, can bring about multiple equilibria.

If the conclusions on the role played by the rating agencies are not unanimous in the theoretical literature, on empirical grounds the prevailing view is that rating agencies do bring new information to markets when they downgrade issuers but not when they improve their ratings. Indeed, significant negative abnormal returns are generally observed in equity and bond markets for issuers after they suffer a rating downgrade, while no (positive) abnormal return is typically detected in conjunction with upgradings (Barron et al., 1997; Ederington and Goh, 1998; Goh and Ederington, 1993, 1999; Griffin and Sanvicente, 1982; Holthausen and Leftwich, 1986; Impson et al., 1992; Liu et al., 1999; Matolcsy and Lianto, 1995; Wansley et al., 1992; Zaima and McCarthy, 1988). ${ }^{4}$

In the following section the experimental design is reported. In section 3 the different treatments are described in details. The results of the experiment are presented in section 4. Section 5 concludes.

\section{The experimental design}

We have a market composed by $n$ agents; each one is endowed - at the beginning of each trading period - with $m$ units of an unspecified asset, and $M$ units of experimental money (actually equivalent to real money as the exchange rate is one for one). This asset pays a single uncertain pay-off at the end of the trading period (i.e. a dividend). Apart from the dividend paid out at the end of each trading period, assets are worthless at the end of the period. There are two equally likely states of the world: i.e. $H$ and $L$. In $H$ the dividend is equal to $d$, in $L$ the dividend is equal to 0 . At the beginning of each trading period the true state of the world is determined by the experimenter -

\footnotetext{
${ }^{4}$ Contrary to most authors, a limited number of papers find evidence of negative abnormal returns following rating downgrades (Glascock et al., 1987; Hsueh and Liu, 1992).
} 
but not revealed to the agents. The agents observe a public signal and can buy private signals - both (public and private) signals are partially but not totally informative as to the true state of the world. Public signals are of a better quality with respect to private ones. These signals take either the value 1 or 0 . More precisely, the probability of getting a public signal of 1 is $P$ if the state of the world is $H$; the probability of getting a public signal of 1 is $1-P$ if the state of the world is $L$, the probability of getting a private signal of 1 is $p$ if the state of the world is $H$; the probability of getting a private signal of 1 is $1-p$ if the state of the world is $L$.

In most respects this experimental design is similar to Hey and Morone (2004), though it differs in the crucial point that subjects receive public information. This is an important change in the experimental design, as it allows us to study whether the presence of public information may act as a sort of disciplining mechanism in the market, promoting the aggregation of noisy information. However, this difference does not change the nature of the solution to the model as agents are informed about relevant parameters - the positive dividend $d$, the cost of buying a signal $c$, and the probabilities $P$ and $p$.

\section{The experimental details}

The experiment was programmed using the z-Tree software of Urs Fischbacher (2007). It was run at the laboratory ESSE at the University of Bari. A Power Point presentation, pre-set to run at a particular speed, was showed on all subjects' computer screens. This was followed by a practice session in which particular subjects were asked to perform particular tasks (make a bid, make an ask, buy, sell, and buy one or more signals). The briefing period lasted some 40 minutes. An example of the Power Point presentation can be found at http://www.dse.uniba.it/istruzioni.

We had $n=15$ agents, each of whom was endowed with 1000 ECU, and 10 units of the asset. The dividend $d$ on each unit of the asset was either 10 ECU or 0 ECU. At the beginning of the trading period the dividend was randomly determined by the experimenter and paid out at the end of the trading period. It was unknown to the agents until the end of the trading period. The experiment 
consisted in 4 "practice" periods and 10 "real" periods. Players were paid only for the profits made over the 10 real periods. Each period lasted 4 minutes; the whole experiment lasted a bit more than one hour and thirty minutes, including reading instructions and the subjects’ payment.

We run six different treatments. Each of them was carried out once. Treatments parameterizations are reported in table 1.

\begin{tabular}{|c|c|c|c|}
\hline Treatment & $P$ & $C$ & $P$ \\
\hline $\mathrm{A}^{5}$ & $60 \%$ & $4 \mathrm{ECU}$ & - \\
\hline $\mathrm{B}$ & $65 \%$ & $4 \mathrm{ECU}$ & - \\
\hline 1 & $55 \%$ & $4 \mathrm{ECU}$ & $75 \%$ \\
\hline 2 & $65 \%$ & $4 \mathrm{ECU}$ & $75 \%$ \\
\hline 3 & $55 \%$ & $4 \mathrm{ECU}$ & $80 \%$ \\
\hline 4 & $65 \%$ & $4 \mathrm{ECU}$ & $80 \%$ \\
\hline 5 & $55 \%$ & $4 \mathrm{ECU}$ & $85 \%$ \\
\hline 6 & $65 \%$ & $4 \mathrm{ECU}$ & $85 \%$ \\
\hline
\end{tabular}

Table 1: Treatments' parameters.

Hey and Morone (2004) showed that herd behaviour might be observed in a market context. Their "results suggest that the volatility of prices is lower (with the implication that herding is less likely) when the quality and the quantity of information in the market are higher”. Quality is an exogenous variable in our experiment and it is a function of the noisiness of the signal. Since we are interested in studying whether public information can stimulate the aggregation of private information we decided to concentrate our study on the cases where private signals are very noisy (i.e. $p=0.55$, and $p=0.65$ ). Quantity is an endogenous variable, we believe it can be influenced, somehow, by the quality of the public information. We predicted that more accurate public information would induce agents to buy fewer private signals.

As far as the private signal probability is concerned, as $p$ rises, the private information becomes more reliable - hence, the quality of the information present in the system improves - and this might produce some considerable effect on price volatility. We shall expect:

(H1) less volatility in Treatment 2 compared to Treatment 1;

(H2) less volatility in Treatment 4 compared to Treatment 3.

\footnotetext{
${ }^{5}$ Source: Treatment 1 in Hey and Morone (2004).
} 
(H3) less volatility in Treatment 6 compared to Treatment 5.

As far as the public signal probability is concerned, as $P$ rises, the public information becomes more reliable ${ }^{6}$ - hence, the quality of the common information present in the system, at the beginning of the trading period, improves - and this might produce some considerable effect on the aggregation of information in the market and so on price volatility. We should expect:

(H4) volatility decreases through treatment 5 , 3, and 1 ;

(H5) volatility decreases through treatment 6, 4, and 2.

\section{Results}

In order to summarise the results of our experiment we report the graphs of the traded prices (figures 1 to 6 ), the dividend, the rating agency signal and the private signal in each of the 10 periods for each treatments. In each graph, on the horizontal axis is plotted time in seconds and the vertical lines break up the experimental session into its 10 market periods ${ }^{7}$. The small blue squares are trades. We have joined together the trades in chronological order. The black diamonds at 12 and at -2 are purchased signals; those plotted at 12 refer to cases where the signal was 1 (suggesting that the true dividend would be 10 ECU) and those plotted at -2 refer to cases where the signal was 0 (suggesting that the true dividend would be 0 ECU). The red lines plotted at 0 or at 10 show the actual true dividend (revealed, recall, to the participants only at the end of the trading period). Finally the green lines plotted at -3 or at 13 show the rating agency signal (revealed to all subjects at the beginning of each periods).

\footnotetext{
${ }^{6}$ The quality of information may vary across rating agencies because of different reasons. For instance, Norden and Weber (2004) show that reviews for downgrade by S\&P and Moody's have the largest impact on credit default swaps and shares, while Ferri (2004) finds that the quality of information implicit in the ratings depends on the effort exerted by the rating agency.

${ }^{7}$ We do not show the results for the four practice periods.
} 


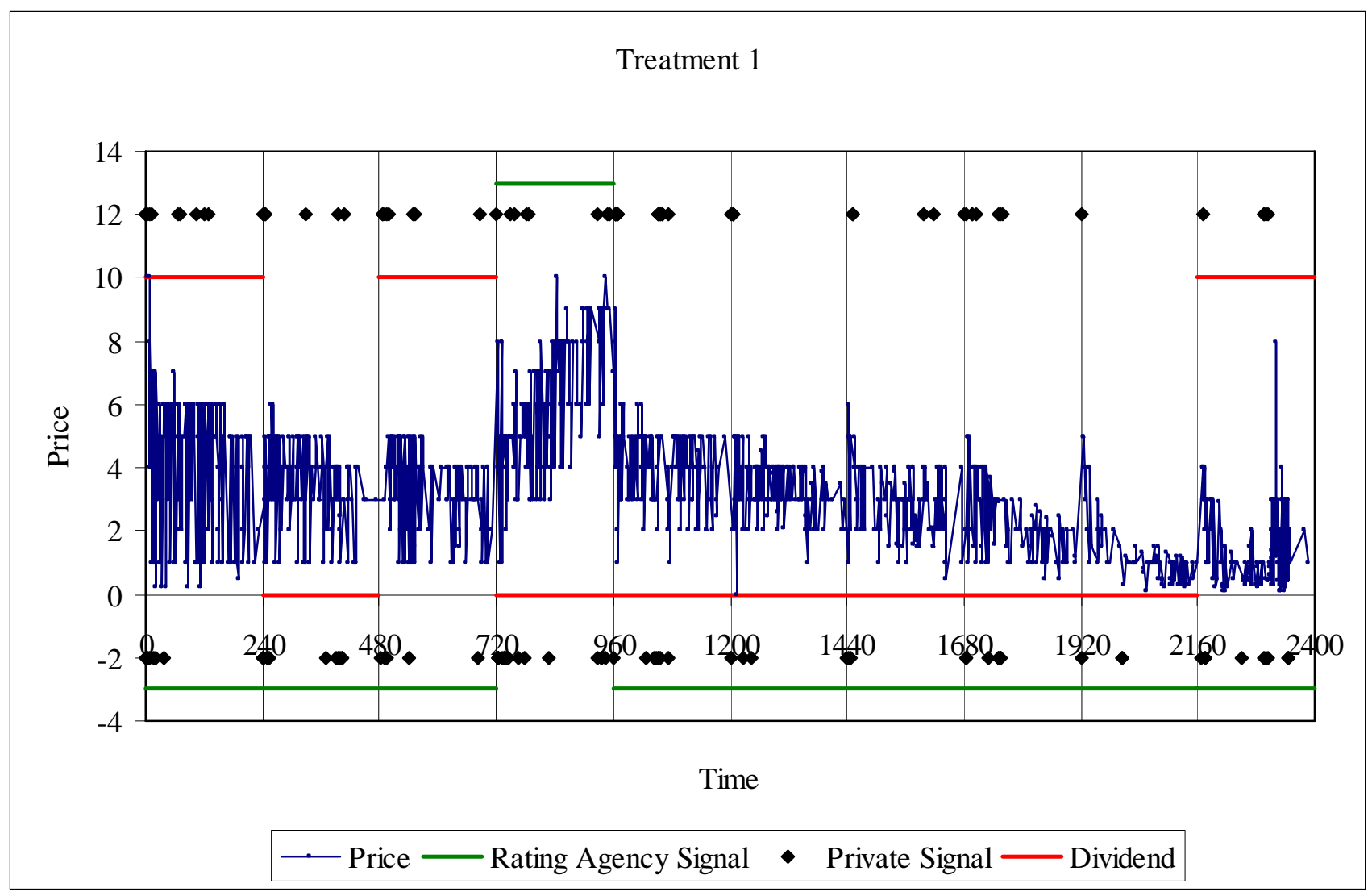

FigURE 1: TRADE IN TREATMENT 1

Treatment 1 . This is characterized by a lot of noise and volatility and a great deal of market activity. In periods $2,5,6,7,8$, and 9 there is a general tendency for the mean price to move in the correct direction, though this is not always the case - in trading periods $1,3,4$, and 10 we can observe a general tendency for the mean price to move in the wrong direction. It is interesting to note that this apparent balance disappears if we relate the general tendency of the mean price to the public signal. In this case we can observe that in all periods the mean price moves in the direction of the public signal. This is clear evidence of the key role played by the rating agency. In this treatment we can observe 2 wrong herds. The more obvious one occurs at period 4; where the assets prices rise up to 9-10. It is interesting to note that the bubble starts at $1 / 3$ of the period, once subjects stop buying private information. The results of this period provide moderate evidence against the prevailing view that rating agencies do bring new information to the market when they downgrade issuers but not when they improve their ratings. The second herd occurs at period 10, also in this case - even though the phenomenon is less strong - it starts once subjects stop buying private signals. Of 
course, we cannot know in which direction causality goes. In other words, does the bubble start when subjects do not buy signals or do subjects stop buying signals once the bubble starts? Though we cannot answer this question we can conclude that herd behaviour can occur if there is a lack of private information.

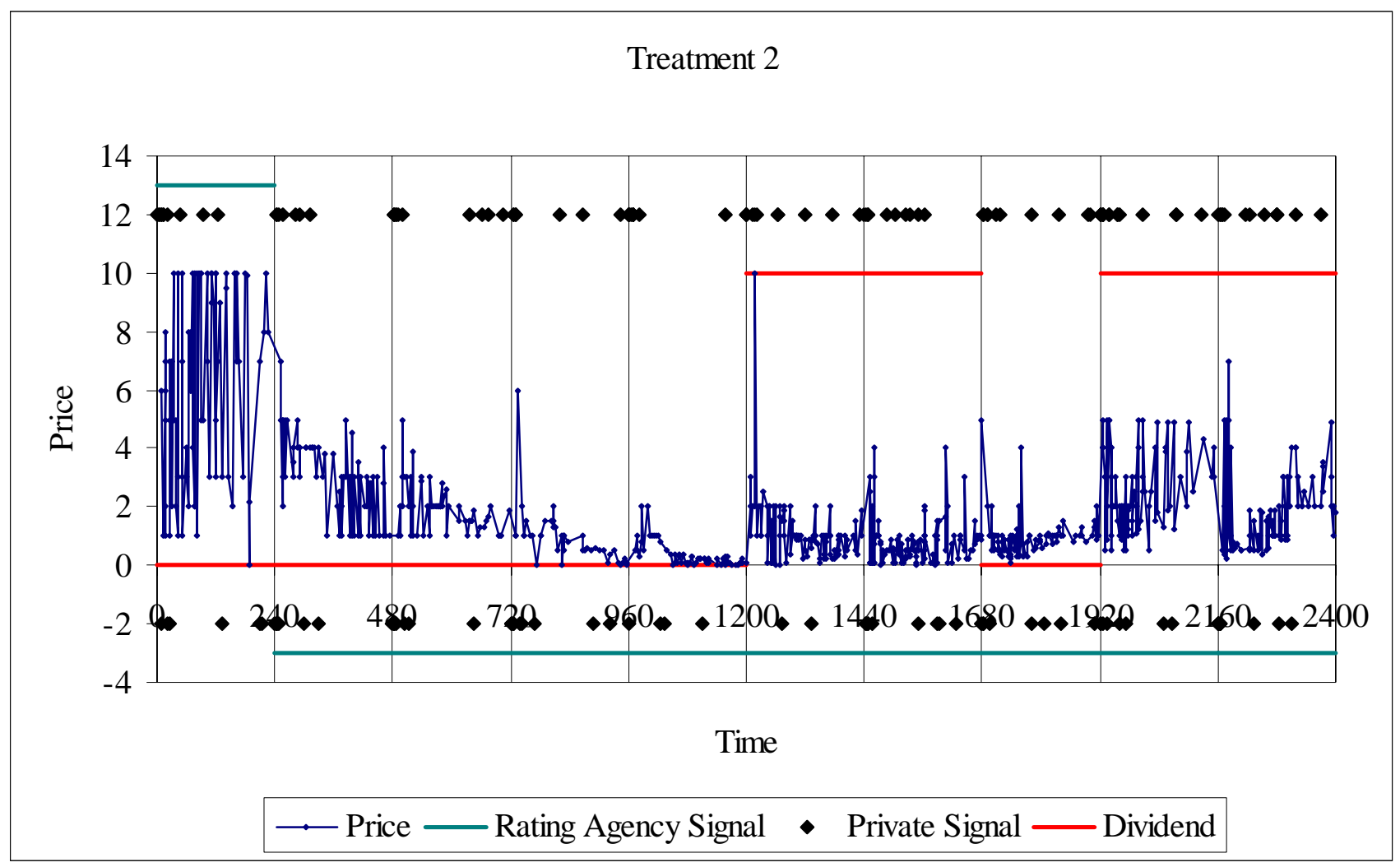

Figure 2: TRADE IN TREATMENT 2

Treatment 2. Also this treatment is characterized by a lot of volatility and a high transactions volume. In figure 6 we report the trading volumes. The volume decreases over time in 6 periods out of 10 , and in the remaining 4 periods it increases over time. It is interesting to note that the volume activity in Treatment 2 is much lower than it was in Treatment 1 . Consistently with Hey and Morone (2004), we can explain this finding referring to the fact that subjects bought more signals (see tables 2 and 3) in Treatment 2 than in Treatment 1 and so they were better informed. 


\begin{tabular}{cccc} 
Period & \# signals & \# 1 & \# 0 \\
\hline 1 & 17 & 10 & 7 \\
2 & 18 & 4 & 14 \\
3 & 13 & 8 & 5 \\
4 & 22 & 8 & 14 \\
5 & 21 & 10 & 11 \\
6 & 7 & 3 & 4 \\
7 & 7 & 4 & 3 \\
8 & 16 & 8 & 8 \\
9 & 4 & 0 & 4 \\
10 & 15 & 6 & 9 \\
\hline T1 & 140 & 61 & 79 \\
\hline
\end{tabular}

Table 2: Treatment 1

\begin{tabular}{cccc} 
Period & \# signals & \# 1 & \# 0 \\
\hline 1 & 17 & 6 & 11 \\
2 & 15 & 2 & 13 \\
3 & 18 & 7 & 11 \\
4 & 16 & 5 & 11 \\
5 & 15 & 4 & 11 \\
6 & 13 & 11 & 2 \\
7 & 19 & 10 & 9 \\
8 & 18 & 6 & 12 \\
9 & 24 & 16 & 8 \\
10 & 24 & 14 & 10 \\
\hline T2 & 179 & 81 & 98 \\
\hline
\end{tabular}

Table 3: Treatment 2

Looking at figure 2 we can conclude that prices converge more often to the true dividend compared to Treatment 1 . This is due to the larger number of signals purchased and to the better quality of the rating agency. In periods $2,3,4,5$, and 8 the rating agency leads the market through a fast convergence to the correct value of the assets. In periods $1,6,7,9$, and 10 the rating agency leads the market through a convergence to the wrong value of the assets. It is interesting to note that in the last two periods the asset price - even though it remains considerably smaller than the correct one -starts rising at the end of each period. 


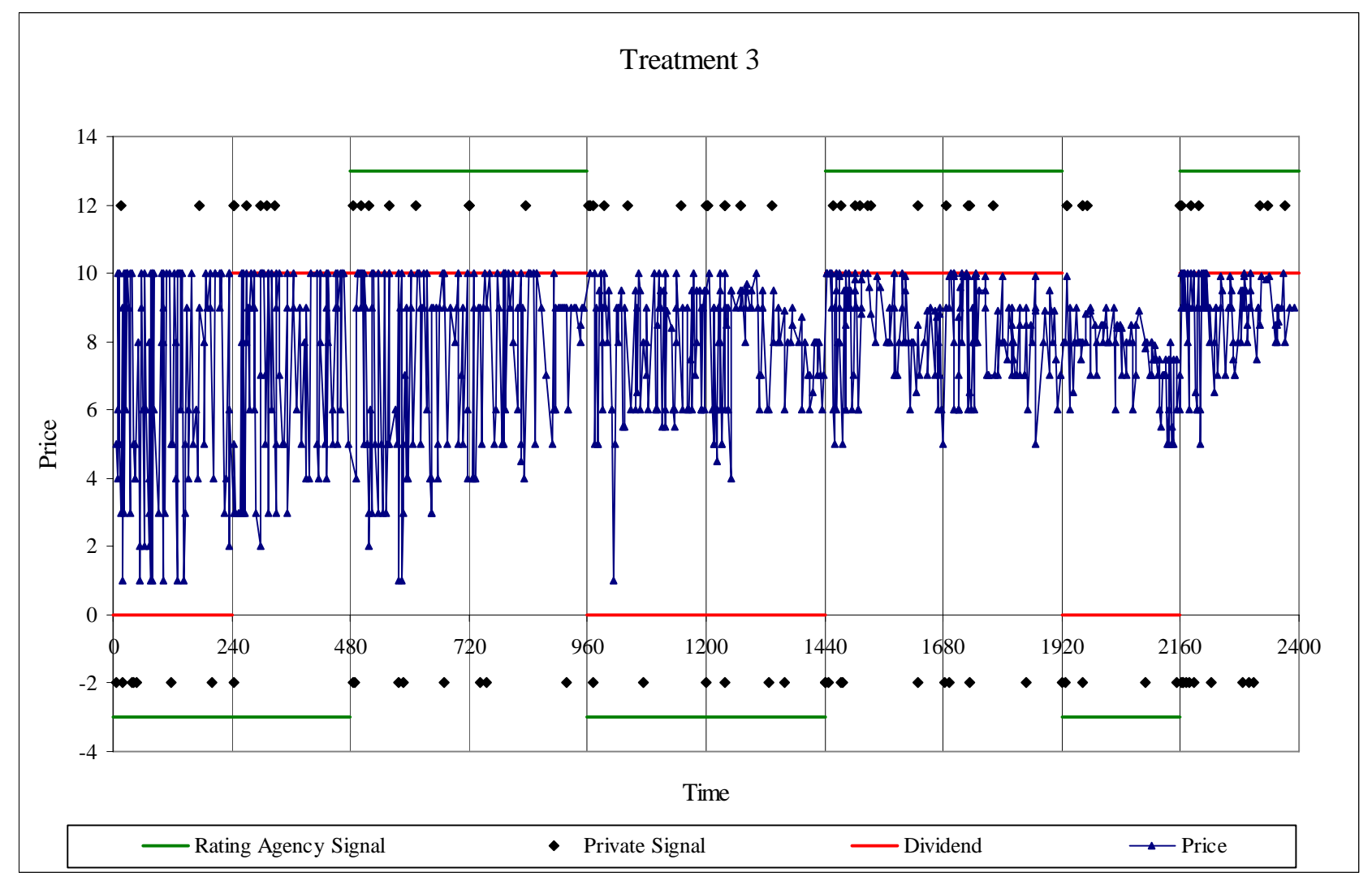

FIGURE 3: TRADE IN TREATMENT 3

Treatment 3 . This is characterized by a great market activity. In periods $2,3,4,7,8$, and 10 there is a general tendency for the mean price to move in the correct direction, though this is not always the case - in period 1 it moves around the uninformed price; in periods 5, 6 and 9 we can observe a general tendency for the mean price to move in the wrong direction, even though at the end of periods 6 and 9 it seems that the bubble bursts and the price fall down.

Treatment 4 is similar to Treatment 3 since we can observe a lot of activity in the market and some bubbles. 


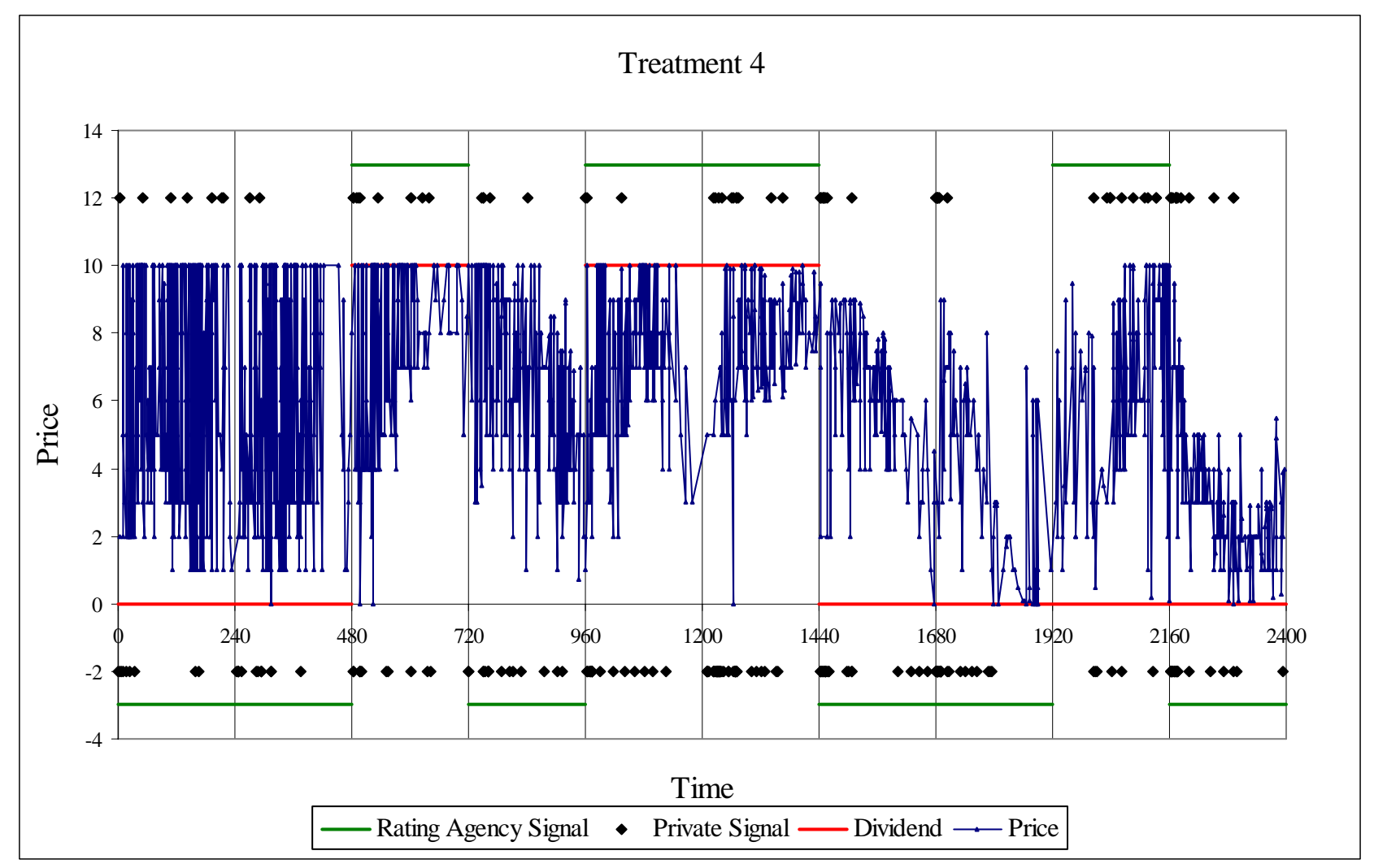

FigURE 4: TRADE IN TREATMENT 4

\begin{tabular}{cccc} 
Period & \# signals & \# 1 & \# 0 \\
\hline 1 & 9 & 2 & 7 \\
2 & 8 & 7 & 1 \\
3 & 10 & 5 & 5 \\
4 & 7 & 4 & 3 \\
5 & 9 & 7 & 2 \\
6 & 11 & 6 & 5 \\
7 & 13 & 7 & 6 \\
8 & 8 & 4 & 4 \\
9 & 10 & 4 & 6 \\
10 & 17 & 7 & 10 \\
\hline T1 & 102 & 53 & 49 \\
\hline
\end{tabular}

Table 4: Treatment 3

\begin{tabular}{cccc} 
Period & \# signals & $\# 1$ & $\# 0$ \\
\hline 1 & 16 & 7 & 9 \\
2 & 16 & 2 & 14 \\
3 & 20 & 13 & 7 \\
4 & 22 & 5 & 17 \\
5 & 21 & 13 & 8 \\
6 & 56 & 33 & 23 \\
7 & 36 & 11 & 25 \\
8 & 38 & 8 & 30 \\
9 & 17 & 11 & 6 \\
10 & 40 & 15 & 25 \\
\hline T2 & 282 & 118 & 164 \\
\hline
\end{tabular}

Table 5: Treatment 4 


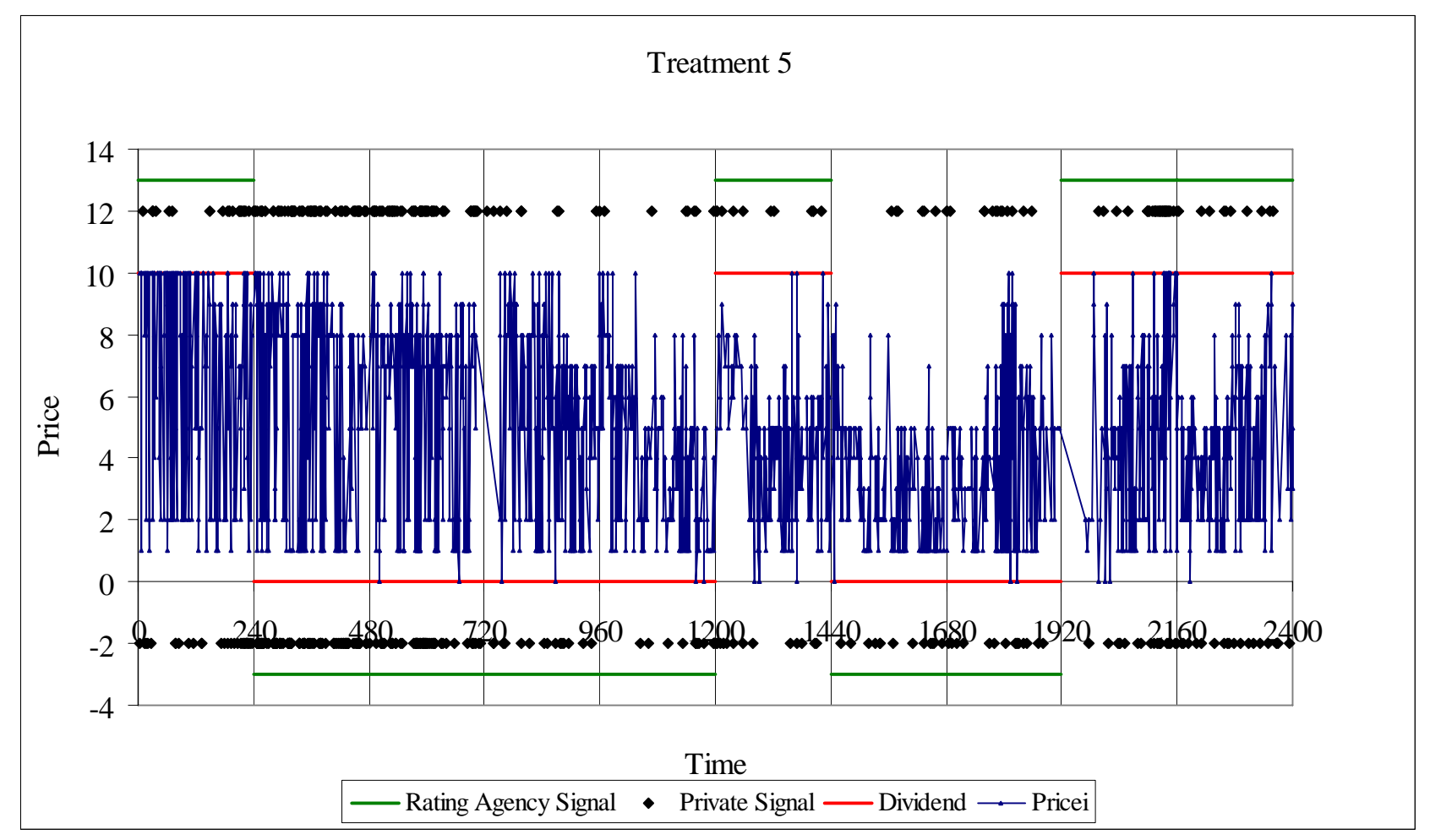

FiguRE 5: TRADE IN TREATMENT 5

Treatment 5. This treatment is different from all the other treatments. Looking at figure 5 we cannot find a particular structure, we can see a lot of noise coupled with a great subject's activity. A possible explanation could be that subjects purchased a lot of private information, but it is very noisy. 


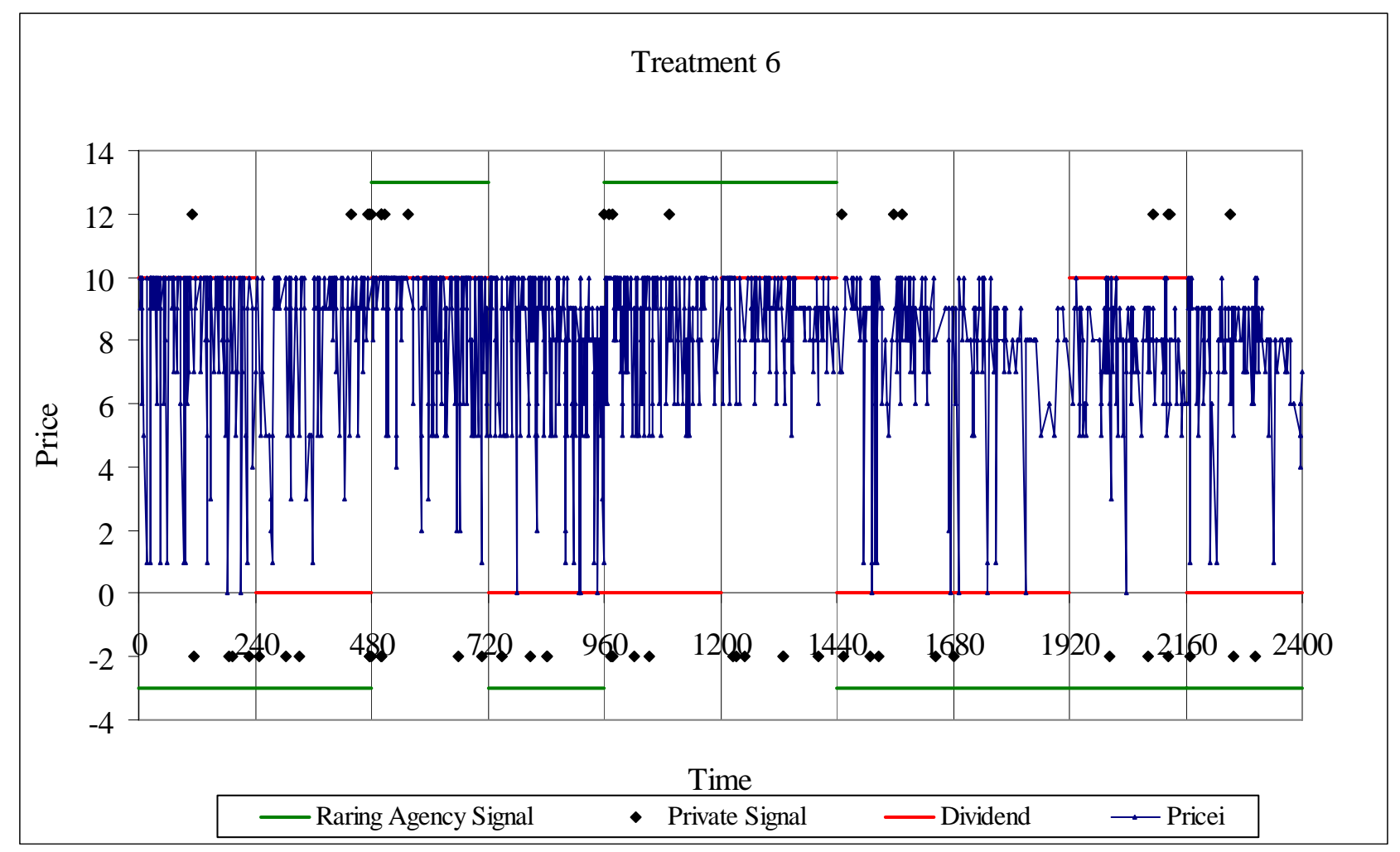

FiguRE 6: TRADE IN TREATMENT 6

\begin{tabular}{cccc} 
Period & \# signals & \# 1 & \# 0 \\
\hline 1 & 51 & 32 & 19 \\
2 & 160 & 68 & 92 \\
3 & 115 & 59 & 56 \\
4 & 25 & 10 & 15 \\
5 & 18 & 7 & 11 \\
6 & 25 & 14 & 11 \\
7 & 19 & 6 & 13 \\
8 & 29 & 14 & 15 \\
9 & 50 & 36 & 14 \\
10 & 29 & 14 & 15 \\
\hline T1 & 521 & 260 & 261 \\
\hline
\end{tabular}

Table 6: Treatment 5

\begin{tabular}{cccc} 
Period & \# signals & \# 1 & \# 0 \\
\hline 1 & 5 & 1 & 4 \\
2 & 11 & 5 & 6 \\
3 & 10 & 6 & 4 \\
4 & 4 & 0 & 4 \\
5 & 9 & 4 & 5 \\
6 & 6 & 1 & 5 \\
7 & 7 & 3 & 4 \\
8 & 1 & 0 & 1 \\
9 & 6 & 4 & 2 \\
10 & 4 & 1 & 3 \\
\hline T2 & 63 & 25 & 38 \\
\hline
\end{tabular}

Table 7: Treatment 6 


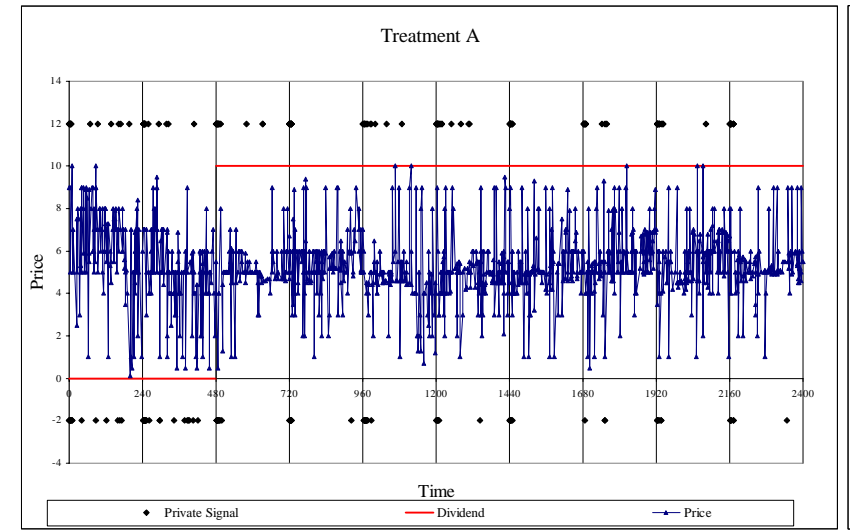

FIGURE 7: TRADE IN TREATMENT A

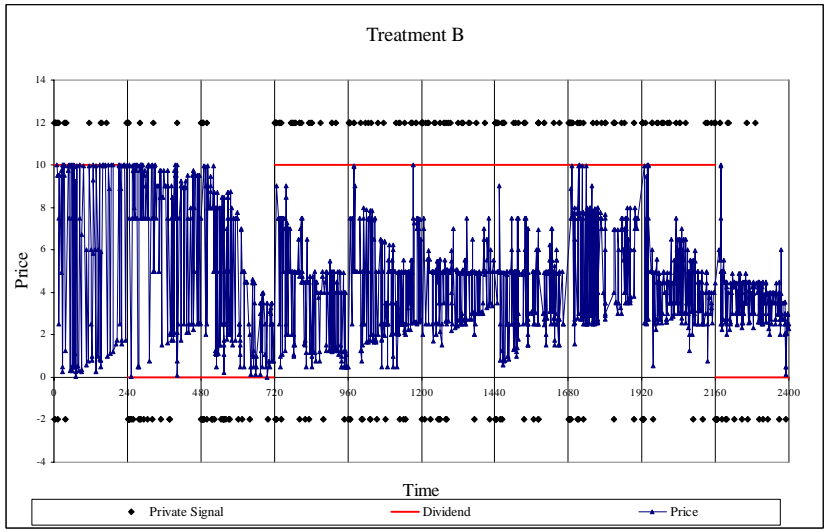

FIGURE 8: TRADE IN TREATMENT B

Consistently with Hey and Morone (2004) and Morone (2008), looking at Figures 1 through Figure 6 we can state that there were a lot of transactions. In order to verify our hypothesis that the presence of the rating agency can improve the efficiency of the market, we tested whether the difference between the assets price and its true value is statistically significantly smaller in the treatment where there is a rating agency (the groups we have compared are reported in table 8).

\begin{tabular}{cc}
\multicolumn{2}{c}{ U-test, two-sided } \\
\hline Group 1 & Group 2 \\
\hline T1, T2, T3, T4, T5, T6 & TA, TB \\
T1 & TA \\
T3 & TA \\
T5 & TA \\
T2 & TB \\
T4 & TB \\
T6 & TB \\
\hline
\end{tabular}

More precisely, using a two sided U-test we verified that this difference is always statistically (0.01) smaller in Group 1.

Further insight into this is given in Figures 9 through Figure 14, which shows the volume of trade minute by minute through each market period. 


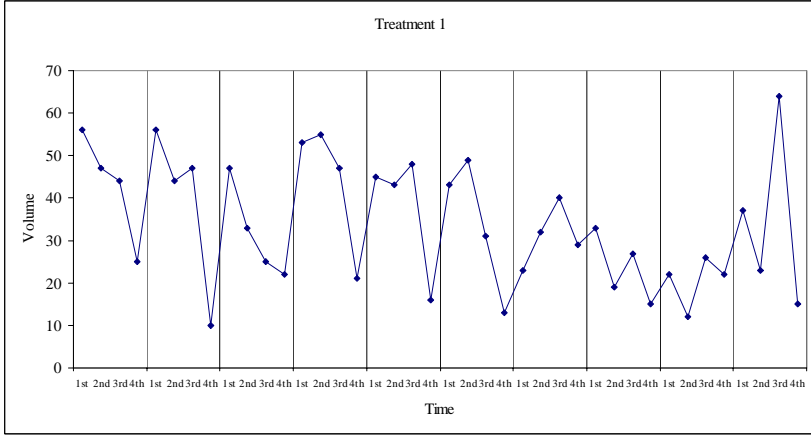

FIGURE 9:

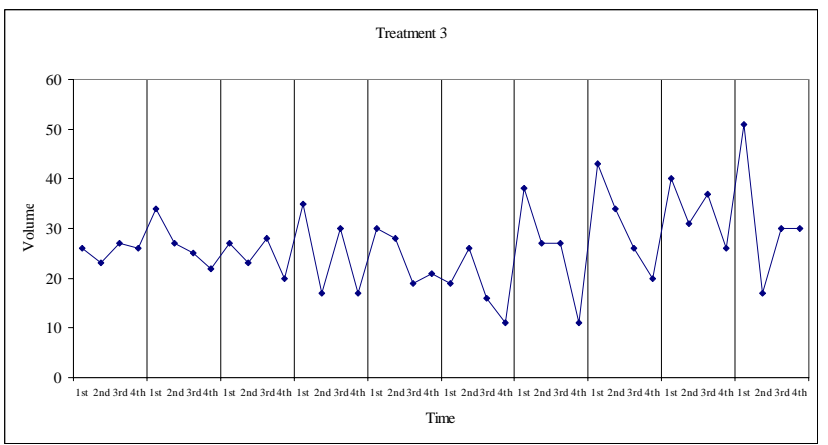

FIGURE 11:

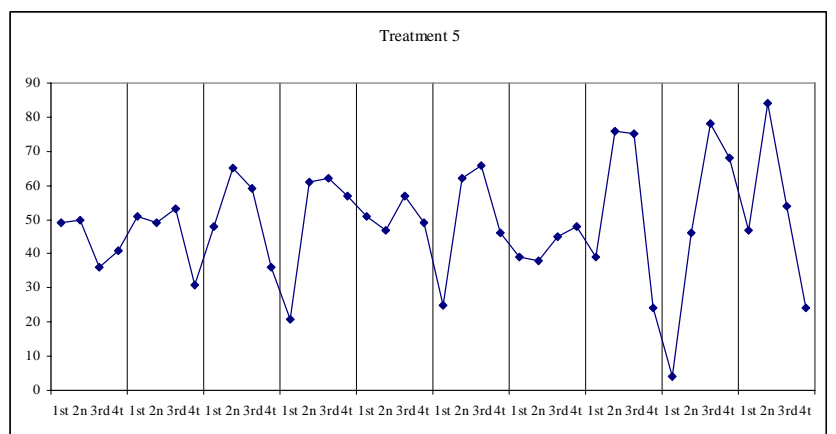

FIGURE 13:

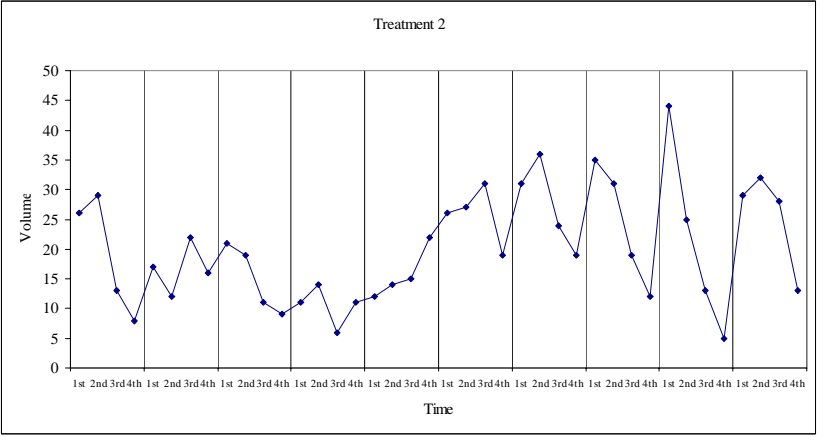

FIGURE 10:

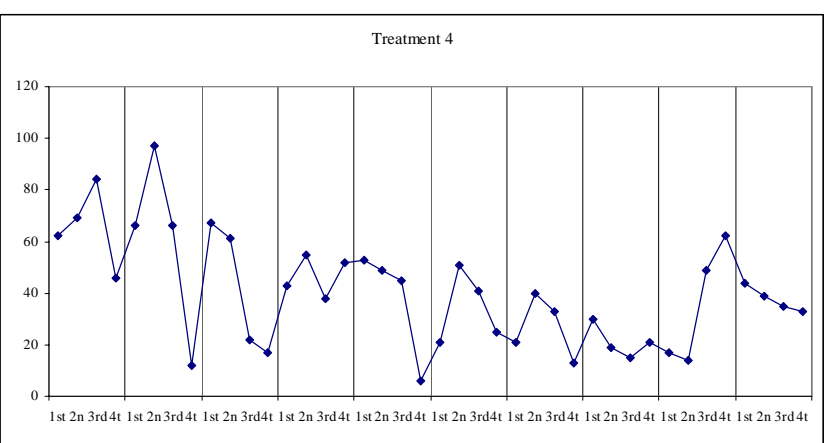

FIGURE 12:

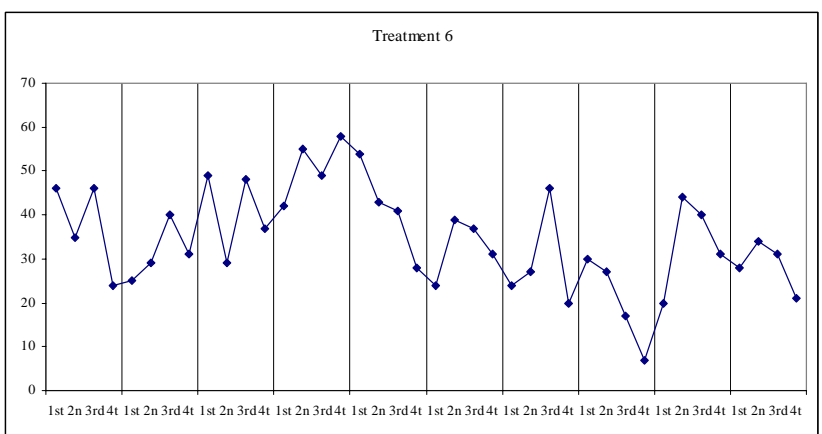

FIGURE 14:

Undoubtedly we can strongly reject the hypothesis of the no-trade equilibrium. Another important result is the positive correlation (see figures 15-20) between the number of trades and the volatility of price (as measured by the variance). This result is important especially if compared to the very little correlation reported in Hey and Morone (2004). 


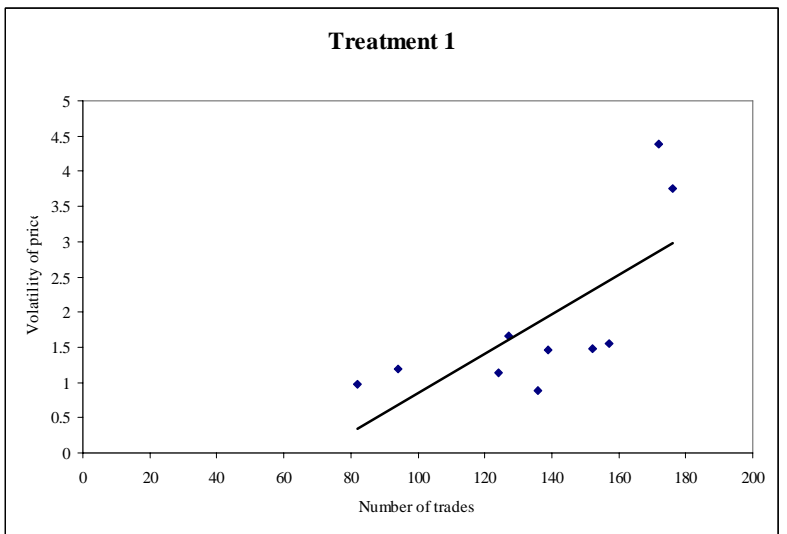

FIGURE 15

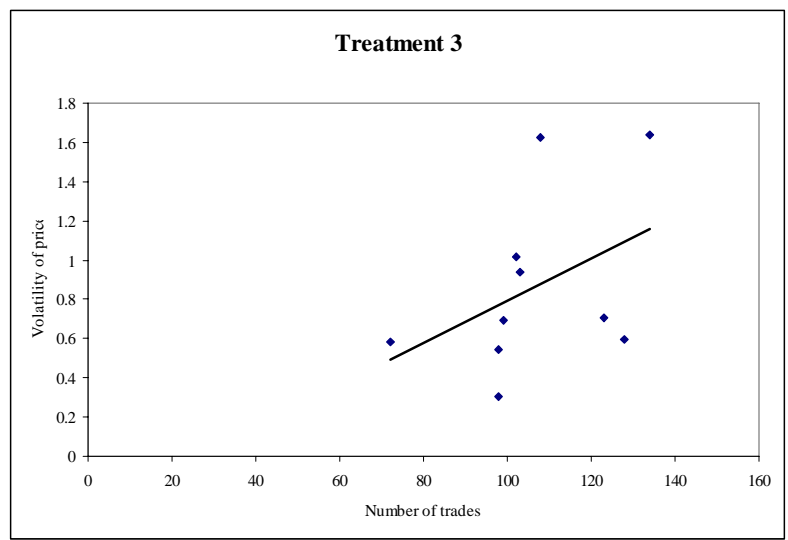

FIGURE 17

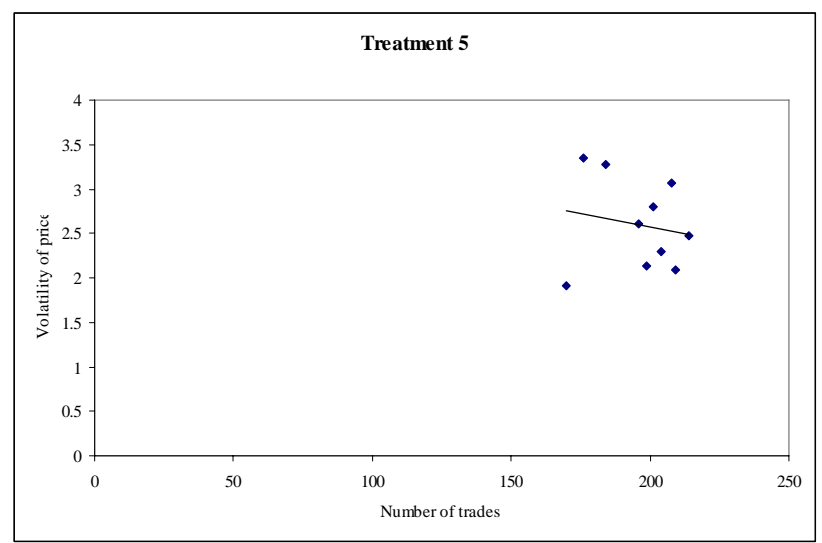

FIGURE 19

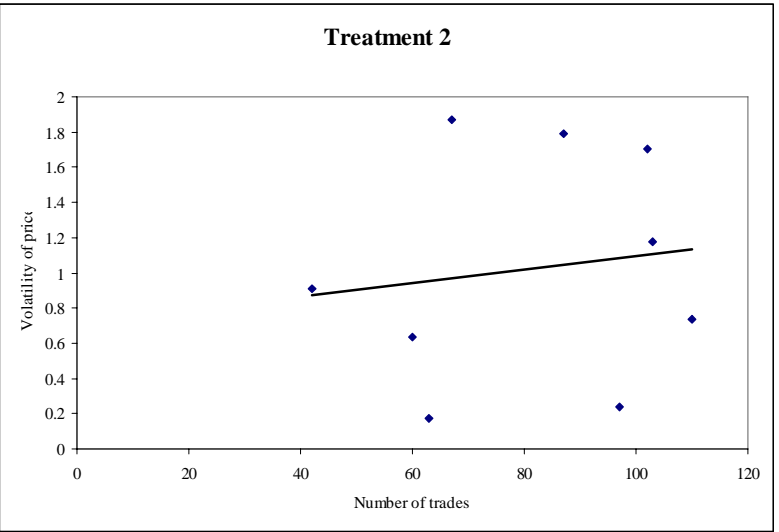

FIGURE 16

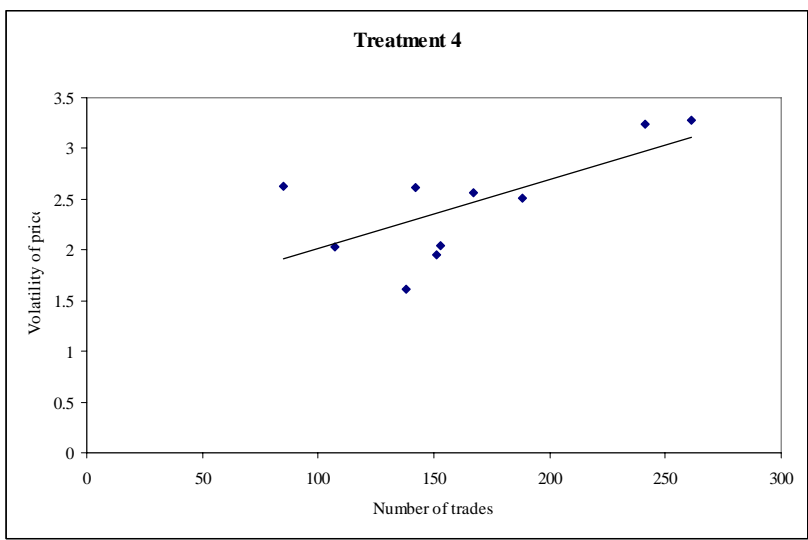

FIGURE 18

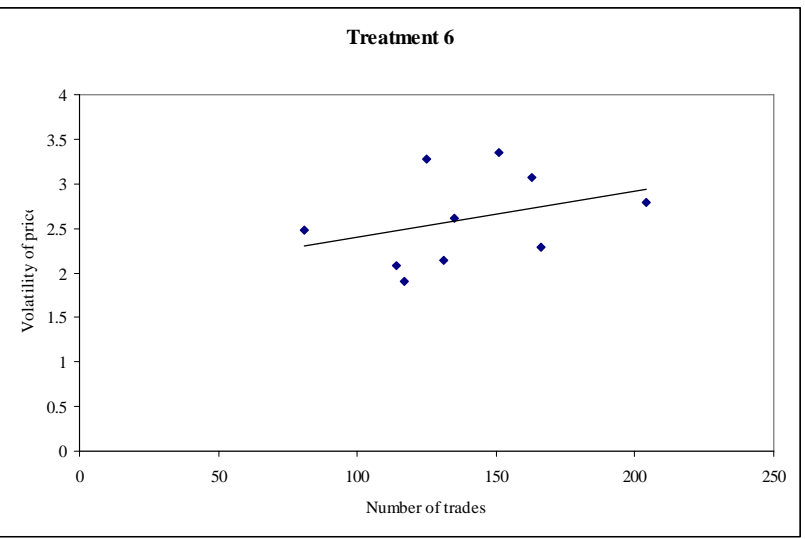

FIGURE 20

Concerning price volatility, looking at figures 21-26 we can observe that volatility decreases through treatments 5, 3, 1 and 6, 4, 2 confirming our hypothesis (H4) and (H5). This result goes in the same direction of what Hey and Morone (2004) observed concerning the role of the quality of information. Indeed, we have a clear negative correlation between quality of information and volatility. Additionally, we can observe that the presence of a rating agency is important to reduce 
the volatility of the price. The more precise is the rating agency the less volatile is the price. Apparently, the quality of the private signal plays a marginal role, since we cannot report a reduction of the volatility moving from Treatments 1 to Treatment 2, or from Treatments 3 to Treatment 4 or from Treatment 5 to Treatment 6 rejecting, hence, our hypotheses (H1), (H2) and (H3).

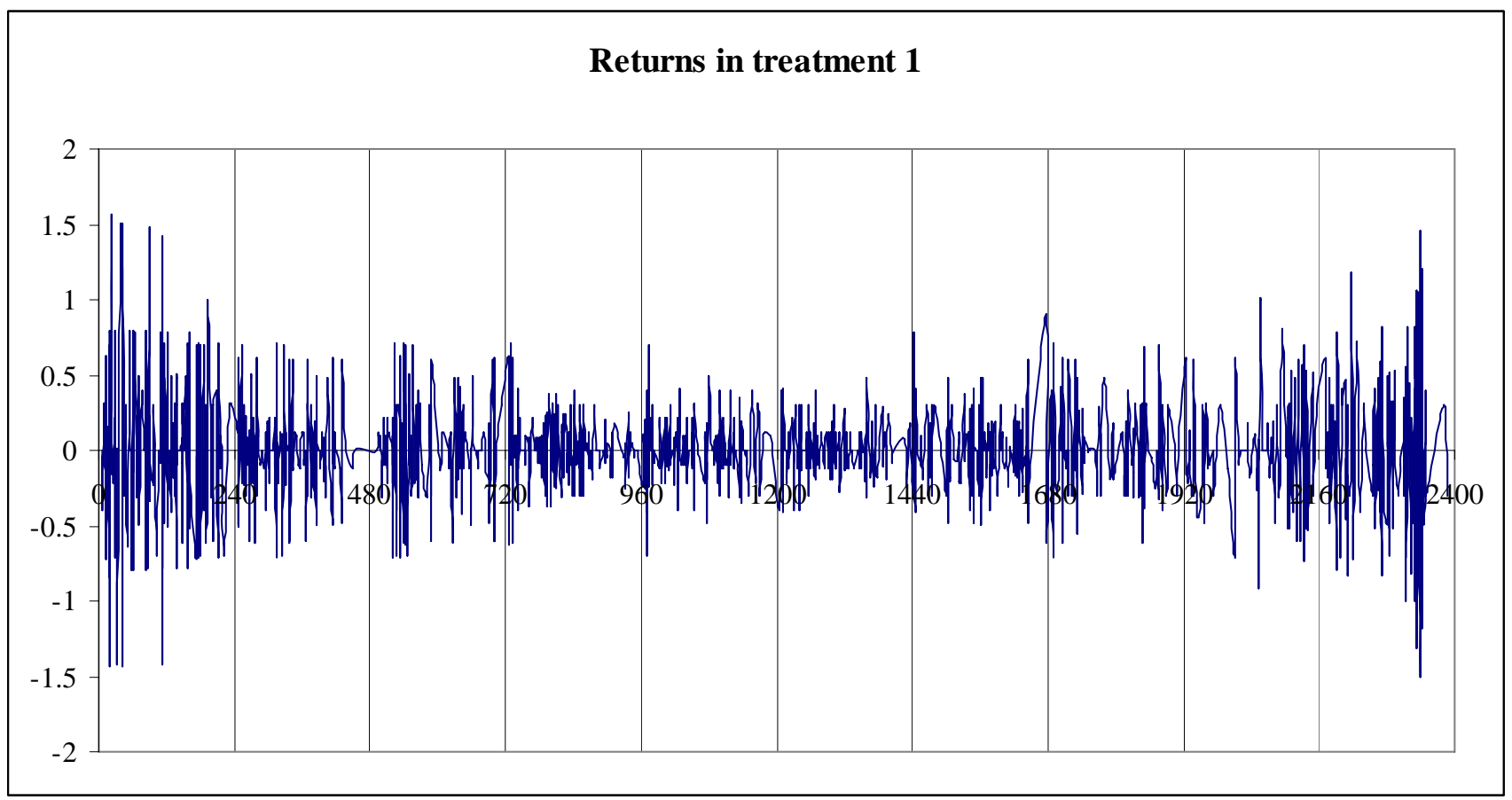



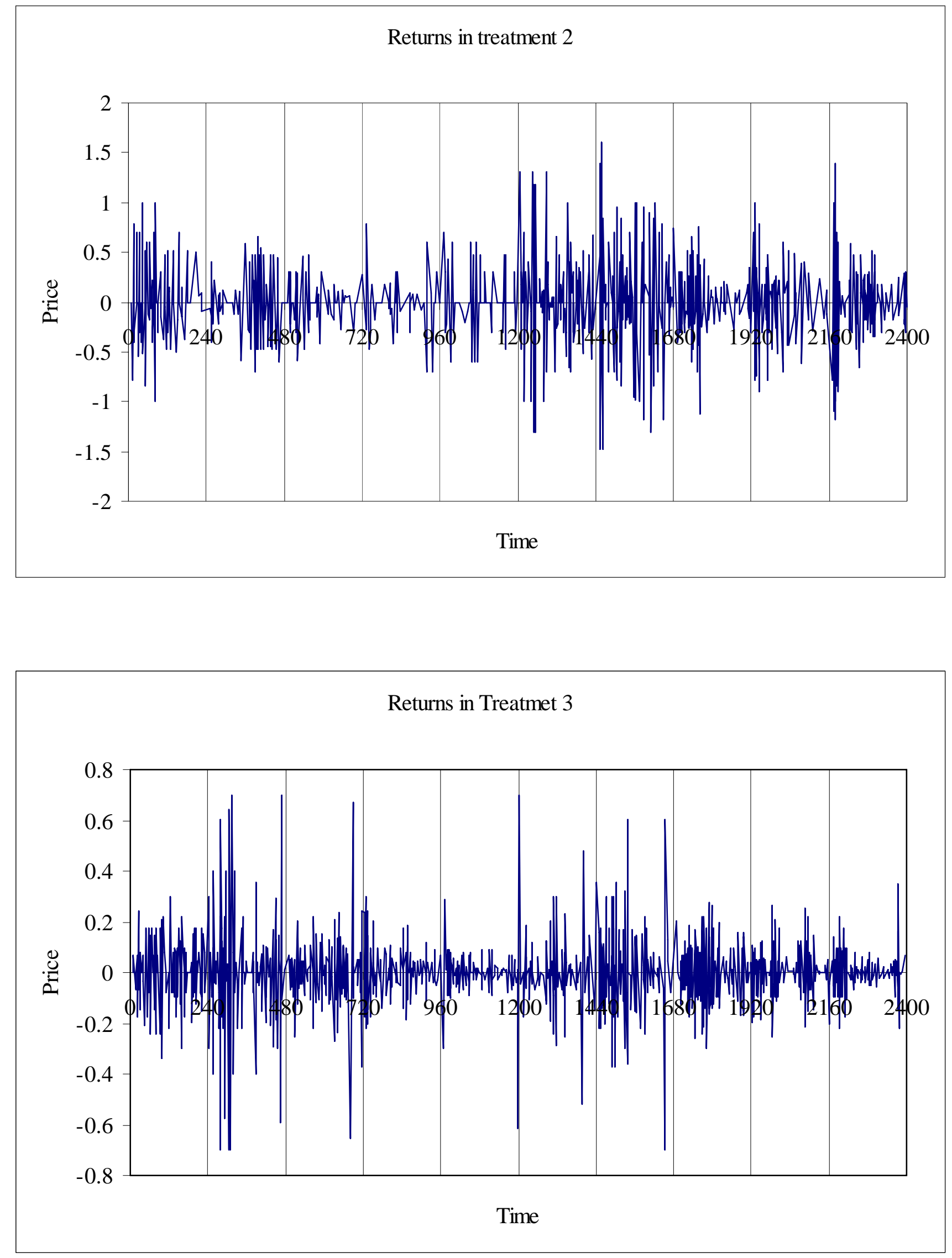

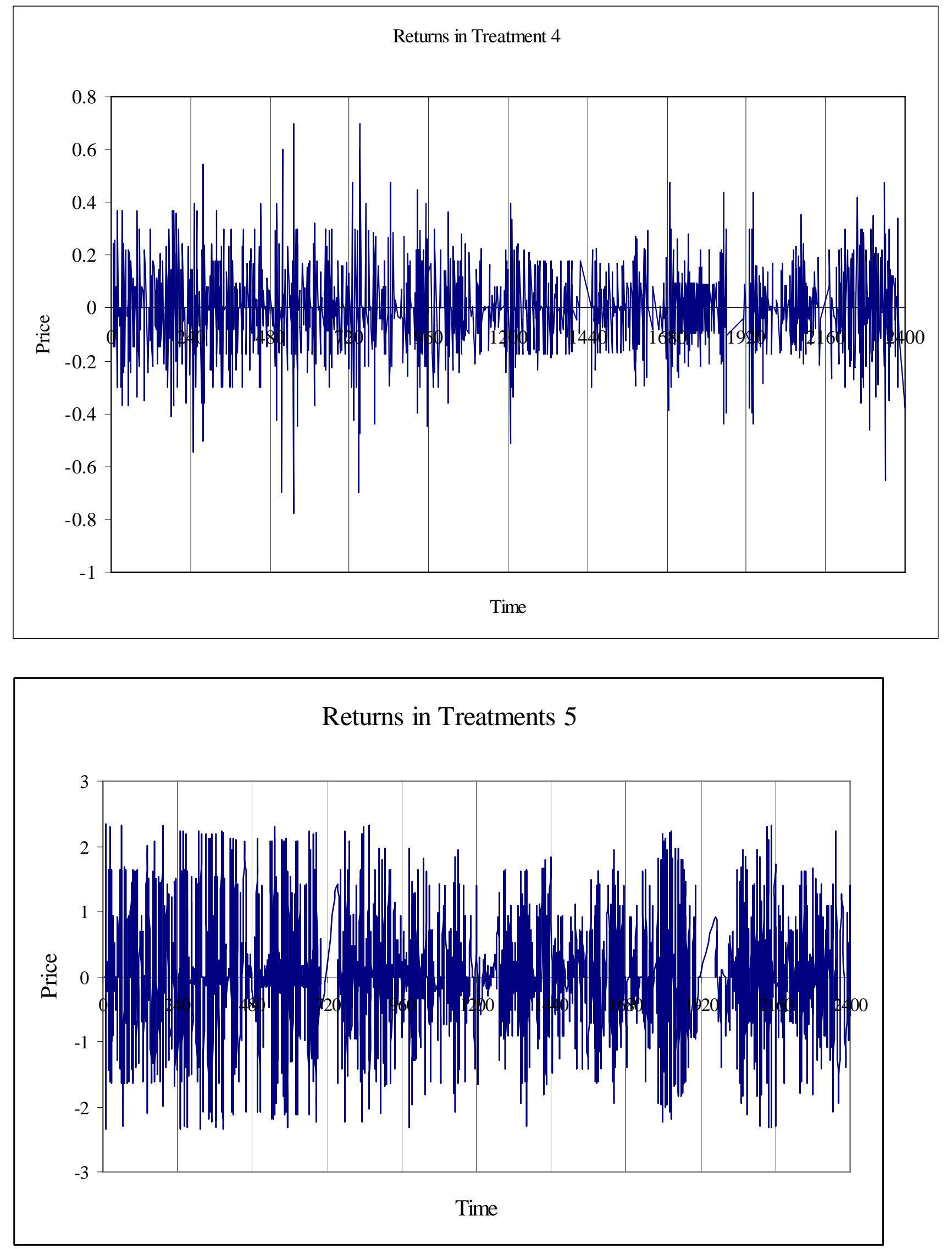


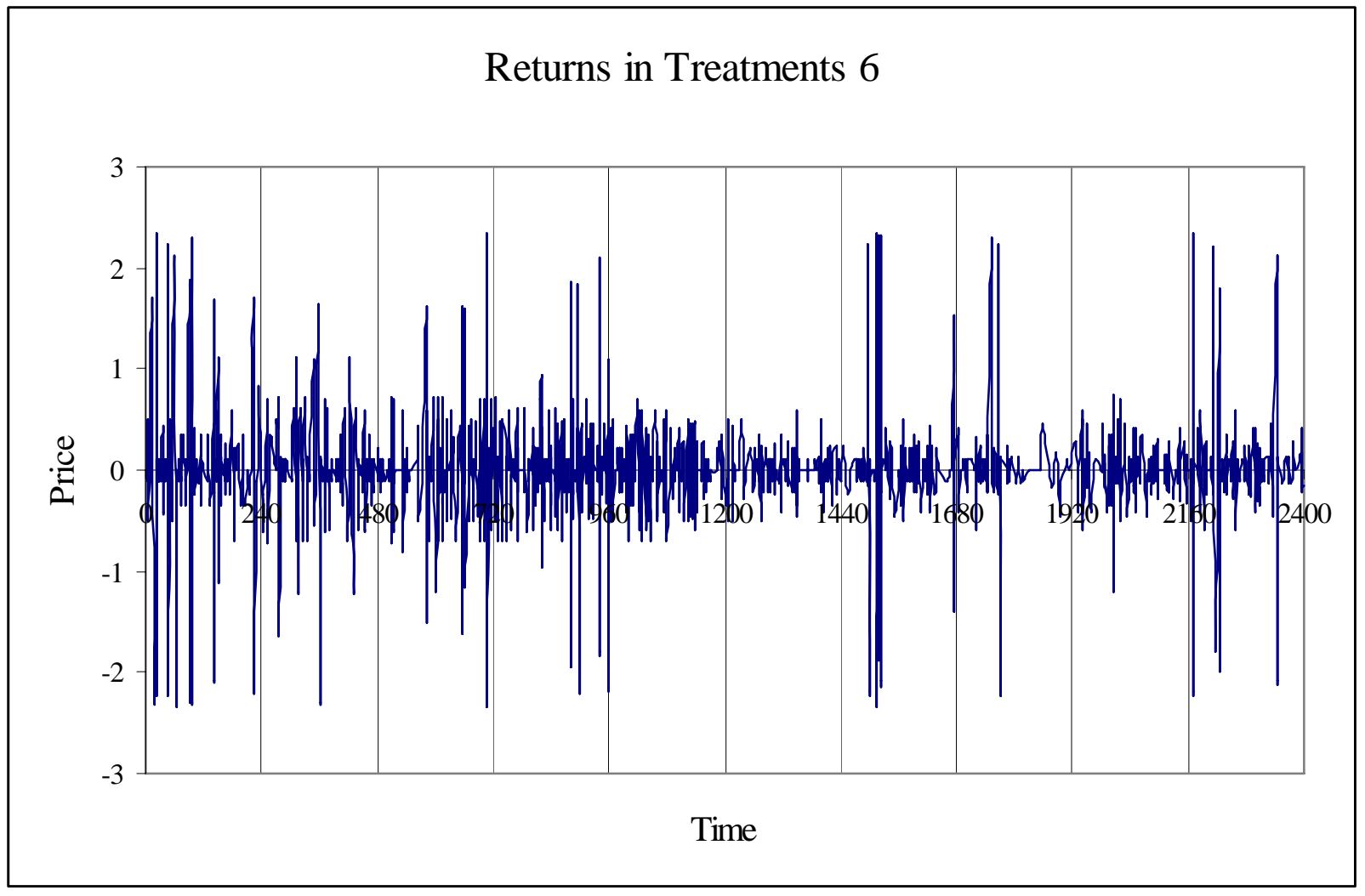

\section{Conclusion}

We used laboratory experiments to investigate whether the introduction of a rating agency in a set up where individuals are otherwise endowed with private information can help the market avoid being stuck in a lemming - generated by wrong herding - and/or help the price converge more quickly to its fundamental value. The rationale behind this expectation was based on two considerations. The first refers to the information structure of the market. Indeed, the rating agency can shun herding and help speed up price convergence because it provides the agents with public information that is better in quality and is also common knowledge to all the agents. The second consideration relates to the massive empirical evidence pinpointing that financial markets show significant reactions to (unexpected) rating changes enacted by the agencies.

We reached two major results showing that, indeed, with the presence of the rating agency the probability of herding is reduced and also price convergence is faster. The former result was obtained taking Hey and Morone (2004) - who showed that lemmings behaviour can survive in a market context where information is private - as the benchmark. Our experiment differed from the 
one they ran only in terms of the public information made available via the rating agency, which may thus be credited as the trigger against herding.

As to the second result, consistently with the findings of Alfarano et al. (2006) - who showed that more information in the market has some effects on trading volume and price volatility - we found that the divergence between the market price and the asset's fundamental value is systematically smaller when the rating agency is present.

\section{References}

Alfarano, S., Barreda-Tarrazona I., and Camacho-Cuena, E., On the role of heterogeneous and imperfect information in a laboratory financial market, Central European Journal of Operations Research, 2006, 14, 4, 417-433.

Allsopp, L. and Hey, J.D., Two Experiments to test a model of herd behaviour, Experimental Economics, 2000, 3, 121-136.

Anderson, L.R. and Holt, C.A., Information Cascades in the Laboratory, American Economic Review, 1997, 87, 847-862.

Banerjee, A. V., A simple model of herd behaviour, Quarterly Journal of Economics, 1992, 107, 797-817.

Barron, M.J., A.D. Clarke, and S.H. Thomas, The Effect of Bond Rating Changes and New Ratings on UK Stock Returns, Journal of Business Finance \& Accounting, 1997, 24, 497509.

Becker, G. S., A Note on Restaurant Pricing and Other Examples of Social Influences on Price, Journal of Political Economy, 1991, 99, 5, 1109-16.

Bikhchandani, S., Hirshleifer, D., and Welch, I., A theory of fads, fashion, customs and cultural change as informational cascades, Journal of Political Economy, 1992, 100, 992-1026.

Boot, A.W.A., T.T. Milbourn, and A. Schmeits, Credit Ratings as Coordinating Mechanism, July WP, 2004.

Carlson, M., and Hale, G., Rating Agencies and Sovereign Debt Rollover, Topics in Macroeconomics, Berkeley Electronic Press, 2006, 6, 2, 1375-1375.

Ederington, L., and J. Goh, Bond Rating Agencies and Stock Analysts: Who Knows What and When?, Journal of Financial and Quantitative Analysis, 1998, 33, 569-585.

Farmer, D., and Joshi, S., The price dynamics of common trading strategies, Journal of Economic Behaviour and Organisation, 2002, 49, 2, 149-171.

Ferri, G., More Analysts, Better Ratings: Do Rating Agencies Invest Enough in Less Developed Countries?, Journal of Applied Economics, 2004.

Fiore, A. and Morone, A., A simple note on informational cascades, Economics - The OpenAccess, Open-Assessment E-Journal, 2008, 2, (1)

Fischbacher, U., Zurich toolbox for readymade economic experiments. Experimental Economics, 2007, 10, 171-178.

Georges C., Learning with misspecification in an artificial currency market, Journal of Economic Behavior and Organization, 2006, 60: 70-84.

Glascock, J.L., W.N. Davidson III, and G.V. Henderson Jr., Announcement effects of Moody's bond rating changes on equity returns, Quarterly Journal of Business and Finance, 1987, 26, 67-78. 
Goh, J. and L. Ederington, Is a Bond Rating Downgrade Bad News, Good News, or No News for Stockholders?, Journal of Finance, 1993, 48, 2001-2008.

Goh, J.C., Ederington, L.H., Cross-sectional variation in the stock market reaction to bond rating changes. Quarterly Review of Economics and Finance, 1999, 39 (1), 101-112.

Griffin, P.A., and A.Z. Sanvincente, Common stock returns and rating changes: a methodological comparison, Journal of Finance, 1982, 47, 733-752.

Grossman S., and Stiglitz, J., Information and Competitive Price Systems, American Economic Review, 1976, 246-253.

Grossman S., and Stiglitz, J., On the Impossibility of Informationally Efficient Markets. American Economic Review, 1980, 70, 393-408.

Hey, J. D., and Morone, A., Do Markets Drive Out Lemmings - or Vice Versa?, Economica, 2004, 71, 637-659.

Holthausen, R.W., and R.W. Leftwich, The effect of bond rating changes on common stock prices. Journal of Financial Economics, 1986, 17 (1), 57-89.

Hsueh, L.P., and Y.A. Liu, Market anticipation and the effect of bond rating changes on common stock prices, Journal of Business Research, 1992, 24, 225-239.

Huber J., Kirchler M., Sutter M., Is more information always better? Experimental financial markets with cumulative information. Journal of Econmic Behavior \& Organization. 2008, 65, 1, 86-104

Impson, C.M., I. Karafiath, and J. Glascock, Testing beta stationarity across bond rating changes, Financial Review, 1992, 27, 607-618.

Kirchler M, Huber J (2006a) Fat tails and volatility clustering in experimental asset markets. Journal of Economic Dynamics and Control, 2007, 31, 6, 1844-1874.

Kuhner, C., Rating Agencies: Are They Credible? - Insights Into the Reporting Incentives of Rating Agencies in Times of Enhanced Systemic Risk, University of Munich, mimeo, 1999.

Liu, P., F.J. Seyyed, and S.D. Smith, The Independent Impact of Credit Rating Changes - The Case of Moody's Ratings Refinements on Yield Premiums, Journal of Business Finance \& Accounting, 1999, 26, 337-63.

Matclosy, Z.P., and T. Lianto, The incremental information content of bond rating revisions: the Australian evidence, Journal of Banking and Finance, 1995, 19, 891-902.

Millon, M.H., and A.V. Thakor, Moral Hazard and Information Sharing: A Model of Financial Information Gathering Agencies, The Journal of Finance, 1985, 40, 1403-1422.

Morone, A., Financial markets in the laboratory: an experimental analysis of some stylized facts Quantitative Finance, 2008, 8, (5), 513-532

Morone, A., Samanidou, E., A simple note on herd behaviour, Journal of Evolutionary Economics, 2008, 18, (5), 639-646

Norden, L., Weber, M., Informational efficiency of credit default swap and stock markets: The impact of credit rating announcements, Journal of Banking \& Finance, 2004, 28, 11, 28132843

Plott, C. R., and Sunder S., Efficiency of Controller Security Markets with Insider Information: An Application of Rational Expectation Models, Journal of Political Economy, 1982, 90, 4, 663698.

Plott, C. R., and Sunder, S., Rational Expectations and the Aggregation of Diverse Information in Laboratory Security Markets, Econometrica, 1988, 56, 5, 1085-1118.

Plott, C. R., Markets as Information Gathering Tools, Southern Economic Journal, 2002, 67, 1-15.

Wansley, J.W., J.L. Glascock, and T.M. Clauretie, Institutional bond pricing and information arrival: The case of bond rating changes. Journal of Business Finance and Accounting, 1992,19 (5), 733-750.

Zaima, J.K., and J. McCarthy, The impact of bond rating changes on common stocks and bonds: tests of the wealth redistribution hypothesis, Financial Review, 1988,.23, 486-498. 